\title{
Efficacy and Safety of Secukinumab in Patients with Plaque Psoriasis and Latent Tuberculosis
}

\author{
Simone Ribero Matteo Licciardello Pietro Quaglino Paolo Dapavo \\ Medical Sciences Department, Section of Dermatology, University of Turin, Turin, Italy
}

\section{Keywords}

Psoriasis $\cdot$ Secukinumab $\cdot$ Latent tuberculosis infection

\begin{abstract}
Upon the association of biologic treatments with reactivation of latent tuberculosis infection (LTBI), screening for Mycobacterium tuberculosis infection and anti-tuberculosis chemoprophylaxis in positive patients are required prior to biologic drug administration. Nevertheless, the risk of infection relapses associated with biologic drugs seems to be different. No cases of reactivation of LTBI have been observed in secukinumab-treated subjects, in contrast with clinical reports on the risk associated with anti-tumor necrosis factor $\alpha$-based therapy. Twelve patients with moderate to severe plaque psoriasis eligible for systemic treatment and found to have LTBI received secukinumab without previous chemoprophylaxis initiation because of clinical contraindication for 10 cases and refusal by 2 patients. None of them had tuberculosis reactivation.




\section{Risk of Latent Tuberculosis Infection Reactivation}

By blocking critical mediators of innate and adaptive immunity, biotherapeutics may carry a risk of increased opportunistic infections [1-5]. Upon the association of biologic treatments with reactivation of latent tuberculosis infection (LTBI), screening for Mycobacterium tuberculosis infection and anti-tuberculosis chemoprophylaxis in positive patients are required prior to biologic drug administration. Nevertheless, the risk associated with biologic drugs seems to be specifically related to the therapy. A complex interplay between the host and the intracellular pathogen M. tuberculosis occurs, and interference with some pathways may affect the safety of biologic treatments. Tumor necrosis factor (TNF) $\alpha$ has an established role in the host defense against intracellular infection by M. tuberculosis, documented clinically by the association of anti-TNF $\alpha$ therapies with reactivation of LTBI in psoriasis and rheumatoid treated patients [3-7]. TNF $\alpha$ contributes to balancing cell survival, apoptosis, and programmed necrosis in M. tuberculosis infections [5, 8]. TNF $\alpha$-mediated apoptosis has a direct antimicrobial effect on intracellular bacilli. In addition, M. tuberculosis and antigens are packaged in apoptotic bodies, thereby eliminating the niche for mycobacterial growth [5, 8]. As a result, treatment with anti-TNF $\alpha$ antibodies may prevent apoptosis of M. tuberculosis-infected macrophages and enhance bacterial growth [5]. Elevated M. tuberculosis infection rates have been reported, in association with anti-TNF $\alpha$ therapies, in subjects with psoriasis and rheumatoid conditions $[3,4,6,7]$.

The role of IL-17A in host resistance to M. tuberculosis is more equivocal [9-13]. IL-17Aproducing $\gamma \delta \mathrm{T}$ cells and CD4+ T cells have been reported to exert either protective or pathologic roles during different phases of M. tuberculosis infection [9-15]. M. tuberculosis infections have been associated with increased IL-17A levels in in vitro human peripheral blood mononuclear cell cultures, in in vivo mouse models, and even in patients with acute tuberculosis [16-19]. Although early granuloma formation may be dependent on IL-17A, IL-17A-induced neutrophil recruitment may also increase pathological lesions and bacterial burden in chronic pulmonary infections $[17,20]$.

In contrast with clinical reports on the risk of infection associated with anti-TNF $\alpha$ treatment, no cases of reactivation of LTBI were observed in the pooled safety analysis of 10 phase II or III clinical trials in patients with moderate to severe plaque psoriasis treated with secukinumab, a fully humanized, monoclonal anti-IL-17A antibody [21]. The studies included in this analysis had a duration of 52 weeks, compared etanercept, a TNF $\alpha$ inhibitor, and secukinumab treatments, were placebo controlled, and included 3,993 subjects in total. Safety data of 5 secukinumab randomized, double-blind, placebo-controlled phase III clinical trials in 2,044 subjects with moderate to severe plaque psoriasis were pooled to identify subjects with LTBI or previously treated TB and examine rates of reactivation. In 132 subjects treated with secukinumab (median duration 364 days) with a history of treated pulmonary TB, no reactivation of LTBI was observed in 25 individuals who tested negative by interferon- $\gamma$ release assay (and receiving no anti-TB medication) and in 107 subjects who tested positive for LTBI and hence received anti-TB medication [22]. In addition, secukinumab was well tolerated in combination with anti-TB therapy in subjects who began chemoprophylaxis for LTBI before randomization and no subjects discontinued secukinumab treatment while receiving chemoprophylaxis. Specifically, the incidence of elevated liver enzymes in isoniazid-treated patients was not increased during secukinumab treatment [23, 24]. 
Adalimumab, a TNF $\alpha$ inhibitor, and secukinumab effects were compared side by side in an $M$. tuberculosis three-dimensional human microgranuloma model. No reactivation of dormant M. tuberculosis was detected after anti-IL-17A treatment, in contrast to anti-TNF $\alpha$ treatment [22].

\section{Screening and Chemoprophylaxis}

Given the limited role exerted by the cytokines different from TNF, data from controlled trials, national registries of biologics, and post-marketing surveillance show that the risk of TB reactivation in patients receiving non-anti-TNF-targeted biologics is negligible [25]. Nevertheless, established guidelines in Europe recommend screening before starting any biologic therapy for psoriasis [26, 27]. Screening for LTBI is based on a diagnostic algorithm that incorporates medical history, chest radiography, and tests that evaluate immunologic response to M. tuberculosis. Several tests are available, with some limitations, such as purified protein derivative skin test using the Mantoux method and in vitro interferon- $\gamma$ release assays [27]. When LTBI is demonstrated or suspected, starting with chemoprophylaxis, prior to biologic treatment for psoriasis, is recommended [26, 27]. The main contraindications remain hypersensitivity to isoniazid and/or rifampicin; pregnancy; concomitant therapy with hepatotoxic drugs; thrombocytopenia (if rifampicin is to be used); alcoholism (increased risk of fulminant hepatitis and peripheral neuropathy with isoniazid); severe alterations of hepatic function; concomitant use of drugs that interact with isoniazid such as benzodiazepines, anticonvulsants, oral anticoagulants, vitamin D, and valproate; malnutrition (increased risk of peripheral neuropathy with isoniazid); diabetes; chronic renal insufficiency (increased risk of peripheral neuropathy with isoniazid) [27]. Although screening for LTBI and chemoprophylaxis for positive patients are recommended prior to biologic therapy, and no distinction among classes or different drugs has been established, the question whether the screening procedures for LTBI would be necessary still needs an answer. Available evidence suggests that it is safe to use IL17 inhibitors in patients with LTBI [28].

\section{Case Series}

Out of the twelve patients, 7 had moderate to severe plaque psoriasis and 5 palmoplantar psoriasis not controlled by topical treatment, with failure of systemic drugs (11 out of 12 subjects), and were found to have LTBI and received secukinumab without previous chemoprophylaxis because of clinical contraindication for 10 cases and refusal by 2 patients. Mean age was 55.9 years (range 29-77), 9 were males, and PASI at baseline ranged between 13 and 27. $60 \%$ of the patients had a scalp involvement of the psoriasis. Screening for LTBI was performed with purified protein derivative skin test. Failed treatments and contraindications to chemoprophylaxis are shown in Table 1 . Secukinumab $300 \mathrm{mg}$ subcutaneous was administered at weeks $0,1,2,3,4$, and subsequently every 4 weeks. Patients were followed-up for 52 weeks, and checked every 8 weeks by clinical observation, chest X-ray, and inflammation marker evaluation (CRP, VES, and blood count). All patients attained either PASI90 or PASI100 during the follow-up period, between week 5 and week 24 , and improvement was maintained 
during the whole 52-week period of follow-up. No signs of tuberculosis reactivation were observed.

\section{Conclusion}

Although guidelines are lacking on this issue, pharmacological evidence and clinical data suggest that secukinumab is not associated with a risk for reactivation of LTBI, and that it could be safely used in patients with psoriasis, demonstrated to have LTBI, eligible for systemic treatment, and who cannot receive tuberculosis chemoprophylaxis.

\section{Key Message}

Clinical and preclinical investigations with secukinumab found no evidence of increased risk of $M$. tuberculosis infections.

\section{Acknowledgement}

Laura Brogelli, PhD, on behalf of Content Ed Net, provided editorial assistance for the preparation of the manuscript.

\section{Statement of Ethics}

The authors declare that the research was conducted in accordance with the World Medical Association Declaration of Helsinki. The patients have given their written informed consent to publish their case, including publication of images.

\section{Disclosure Statement}

The authors have no conflicts of interest to declare.

\section{Funding Sources}

Editorial assistance was funded by Novartis Farma Italy.

\section{Author Contributions}

All the authors contributed to study design, data collection, and study execution as well as to manuscript preparation. 


\section{References}

1 Maródi L, Casanova JL. Primary immunodeficiencies may reveal potential infectious diseases associated with immune-targeting mAb treatments. J Allergy Clin Immunol. 2010 Nov;126(5):910-7.

2 Cypowyj S, Picard C, Maródi L, Casanova JL, Puel A. Immunity to infection in IL-17-deficient mice and humans. Eur J Immunol. 2012 Sep;42(9):2246-54.

3 Minozzi S, Bonovas S, Lytras T, et al. Risk of infections using anti-TNF agents in rheumatoid arthritis, psoriatic arthritis, and ankylosing spondylitis: a systematic review and meta-analysis. Expert Opin Drug Saf. 2016 Dec;15(sup1):11-34.

4 Ergun T, Seckin D, Baskan Bulbul E, Onsun N, Ozgen Z, Unalan P, et al. The risk of tuberculosis in patients with psoriasis treated with anti-tumor necrosis factor agents. Int J Dermatol. 2015;54(5):594-9.

5 Harris J, Keane J. How tumour necrosis factor blockers interfere with tuberculosis immunity. Clin Exp Immunol. 2010 Jul;161(1):1-9.

6 Winthrop KL, Baxter R, Liu L, Varley CD, Curtis JR, Baddley JW, et al. Mycobacterial diseases and antitumour necrosis factor therapy in USA. Ann Rheum Dis. 2013 Jan;72(1):37-42.

7 Guinard E, Bulai Livideanu C, Barthélémy H, Viguier M, Reguiai Z, Richard MA, et al.; French Psoriasis Research Group. Active tuberculosis in psoriasis patients treated with TNF antagonists: a French nationwide retrospective study. J Eur Acad Dermatol Venereol. 2016 Aug;30(8):1336-41.

8 Moraco AH, Kornfeld H. Cell death and autophagy in tuberculosis. Semin Immunol. 2014 Dec;26(6):497-511.

9 Torrado E, Cooper AM. IL-17 and Th17 cells in tuberculosis. Cytokine Growth Factor Rev. 2010c Dec;21(6):455-62.

10 Mourik BC, Lubberts E, de Steenwinkel JE, Ottenhoff TH, Leenen PJ. Interactions between type 1 interferons and the Th17 response in tuberculosis: lessons learned from autoimmune diseases. Front Immunol. 2017 Apr;8:294.

11 Domingo-Gonzalez R, Prince 0, Cooper A, Khader SA. Cytokines and chemokines in Mycobacterium tuberculosis infection. Microbiol Spectr. 2016 Oct;4(5):4.

12 Das S, Khader S. Yin and yang of interleukin-17 in host immunity to infection. F1000 Res. 2017y May;6:741.

13 Robinson RT, Huppler AR. The Goldilocks model of immune symbiosis with Mycobacteria and Candida colonizers. Cytokine. 2017 Sep;97:49-65.

14 Papotto PH, Ribot JC, Silva-Santos B. IL-17+ $\gamma \delta$ T cells as kick-starters of inflammation. Nat Immunol. 2017 May;18(6):604-11.

15 Veldhoen M. Interleukin 17 is a chief orchestrator of immunity. Nat Immunol. 2017 May;18(6):612-21.

16 Peng MY, Wang ZH, Yao CY, Jiang LN, Jin QL, Wang J, et al. Interleukin 17-producing gamma delta T cells increased in patients with active pulmonary tuberculosis. Cell Mol Immunol. 2008 Jun;5(3):203-8.

17 Okamoto Yoshida Y, Umemura M, Yahagi A, O'Brien RL, et al. Essential role of IL-17A in the formation of a mycobacterial infection-induced granuloma in the lung. J Immunol. 2010 Apr 15;184(8):4414-22.

18 Freches D, Korf H, Denis O, Havaux X, Huygen K, Romano M. Mice genetically inactivated in interleukin-17A receptor are defective in long-term control of Mycobacterium tuberculosis infection. Immunology. 2013 Oct;140(2):220-31.

19 Gopal R, Monin L, Slight S, Uche U, Blanchard E, Fallert Junecko BA, et al. Unexpected role for IL-17 in protective immunity against hypervirulent Mycobacterium tuberculosis HN878 infection. PLoS Pathog. 2014 May;10(5):e1004099.

20 Lowe DM, Redford PS, Wilkinson RJ, O'Garra A, Martineau AR. Neutrophils in tuberculosis: friend or foe? Trends Immunol. 2012 Jan;33(1):14-25.

21 van de Kerkhof PC, Griffiths CE, Reich K, Leonardi CL, Blauvelt A, Tsai TF, et al. Secukinumab long-term safety experience: A pooled analysis of 10 phase II and III clinical studies in patients with moderate to severe plaque psoriasis. J Am Acad Dermatol. 20161 Jul;75(1):83-98.e4.

22 Kammüller M, Tsai TF, Griffiths CE, Kapoor N, Kolattukudy PE, Brees D, et al. Inhibition of IL-17A by secukinumab shows no evidence of increased Mycobacterium tuberculosis infections. Clin Transl Immunology. 2017 Aug;6(8):e152.

23 Haroon M, Martin U, Devlin J. High incidence of intolerance to tuberculosis chemoprophylaxis. Rheumatol Int. 2012 Jan;32(1):33-7.

24 Ai JW, Ruan QL, Liu QH, Zhang WH. Updates on the risk factors for latent tuberculosis reactivation and their managements. Emerg Microbes Infect. 2016 Feb;5(1):e10.

25 Cantini F, Nannini C, Niccoli L, Petrone L, Ippolito G, Goletti D. Risk of Tuberculosis Reactivation in Patients with Rheumatoid Arthritis, Ankylosing Spondylitis, and Psoriatic Arthritis Receiving Non-Anti-TNF-Targeted Biologics. Mediators Inflamm. 2017;2017:8909834. 
26 Nast A, Spuls PI, van der Kraaij G, Gisondi P, Paul C, Ormerod AD, et al. European S3-Guideline on the systemic treatment of psoriasis vulgaris - Update Apremilast and Secukinumab - EDF in cooperation with EADV and IPC. J Eur Acad Dermatol Venereol. 2017 Dec;31(12):1951-63.

27 Gisondi P, Altomare G, Ayala F, Bardazzi F, Bianchi L, Chiricozzi A, et al. Italian guidelines on the systemic treatments of moderate-to-severe plaque psoriasis. J Eur Acad Dermatol Venereol. 2017 May;31(5):774-90.

28 Kaushik SB, Lebwohl MG. Psoriasis: Which therapy for which patient: Focus on special populations and chronic infections. J Am Acad Dermatol. 2019 Jan;80(1):43-53.

Table 1. Failed treatments and contraindications to chemoprophylaxis

\begin{tabular}{|c|c|c|c|c|}
\hline $\begin{array}{l}\text { Patient } \\
\text { No. }\end{array}$ & Sex & Age & Previous failed treatment & Reason not to perform prophylactic therapy \\
\hline 1 & M & 37 & $\begin{array}{l}\text { Cyclosporine, methotrexate } \\
15 \mathrm{mg} / \text { week }\end{array}$ & $\begin{array}{l}\text { Hepatotoxicity was reported during treatment with } \\
\text { methotrexate }\end{array}$ \\
\hline 2 & $\mathrm{M}$ & 77 & Cyclosporine $3 \mathrm{mg} / \mathrm{kg}$ & Hypercholesterolemia \\
\hline 3 & $\mathrm{~F}$ & 68 & & $\begin{array}{l}\text { Increased liver enzymes due to treatment with } \\
\text { carbamazepine }(400 \mathrm{mg} \times 3 / \text { die })\end{array}$ \\
\hline 4 & M & 73 & Acitretin & $\begin{array}{l}\text { Autoimmune hepatitis in treatment with azathioprine } \\
100 \mathrm{mg} \times 2 / \text { die and prednisone } 10 \mathrm{mg} / \text { die }\end{array}$ \\
\hline 5 & M & 53 & Cyclosporine & $\begin{array}{l}\text { Antiviral therapy with high level of liver enzymes for } \\
\text { treatment of HCV infection }\end{array}$ \\
\hline 6 & M & 63 & Methotrexate & $\begin{array}{l}\text { Pulmonary fibrosis and hepatotoxicity, methotrexate } \\
\text { related }\end{array}$ \\
\hline 7 & $\mathrm{~F}$ & 50 & Acitretin, methotrexate & Refused the prophylactic therapy \\
\hline 8 & M & 64 & Cyclosporine, methotrexate & Methotrexate hepatotoxicity \\
\hline 9 & M & 38 & Cyclosporine & Alcoholism \\
\hline 10 & M & 29 & Cyclosporine, methotrexate & Refused the prophylactic therapy \\
\hline 11 & M & 73 & Acitretin $25 \mathrm{mg}$ and methotrexate & Elevation of liver enzymes due to the statin therapy \\
\hline 12 & $\mathrm{~F}$ & 46 & Cyclosporine & Poor tolerability to prophylactic therapy \\
\hline
\end{tabular}

